\title{
La verdad de Hermes. Sobre la autoridad en los textos etnográficos
}

\author{
Annette Leibing*
}

\begin{abstract}
Four different "schools" of qualitative approaches to ethnographic writing are analyzed regarding the role of the author/writer: Naturalism, ethnomethodology, emotionalism and posmodernism (if there is such). Each show the author from a different position, exploring different angles of the world under research. It is argued that the combination of these four "schools", each with its own limitations and revelations, would lead to a broader understanding of the other and ourselves.
\end{abstract}

\section{Resumen}

Se analizan cuatro "escuelas" de enfoques cualitativos para la escritura etnográfica sobre la base del rol de autor/escritor: Naturalismo, etnometodología, emocionalismo y posmodernismo (si es que tal enfoque existe). En cada uno de estos enfoques el autor se expresa desde posiciones diferentes, explorando asi, desde distintos ángulos, la realidad en estudio. Finalmente, se arguye que la combinación de estas cuatro "escuelas", cada una con sus propias limitaciones y revelaciones, podría conducir a un entendimiento más amplio de los demás y de nosotros mismos.

\section{Introducción}

$\mathrm{H}$ ermes prometió no decir más mentiras - pero al mismo tiempo no dijo que iba a decir toda la verdad - y Zeus entendió. Esta metáfora la usó Crapanzano en su ensayo "Hermes' Dilemma" para colocar la cuestión de la verdad en el foco de la discusión en torno de las representaciones etnográficas. Todas las metodologías, pero más explícitamente las cualitativas, tienen a la persona del autor como autoridad y "esta sombra que el etnógrafo lanza encima del escrito"
(Crapanzano, 1986) - al fin él es el Hermes "hermenéutico"- es una fuente importante de datos.

¿Existe, entonces, una realidad con la cual podamos trabajar? Las metodologías cuantitativas objetivizan el mundo - un mundo aparentemente coherente- en la búsqueda de leyes universales y la cuestión por la verdad no tiene mucho sentido. Pero si es el autor, o mejor aún, "el ojo del etnógrafo" (M. Leiris), el que construye la verdad, y el objeto observado no es ontológico: ¿para qué sirve esa relativización de lo real en las metodologías cualitativas? Podemos partir de la premisa que las metodologías cuantitativas y cualitativas hacen preguntas diferentes ${ }^{1}$ - revelan diferentes visiones del mundo y la búsqueda por la verdad solamente tiene sentido cuando es hecha dentro del universo a ser investigado. Entiendo la metodología cualitativa como complementaria a la cuantitativa, algo que Max Weber ya había propuesto para una sociología interpretativa. Rorty en este sentido, afirma que "para decir que una cosa está mejor 'entendida' en un vocabulario más que en otro, siempre es una elipse para la exigencia de que una descripción en un vocabulario preferido es el más útil para un determinado fin" (1994:52).

Quiero enfocar en este texto la figura del autor y la identificación del mismo en algunos abordajes cualitativos. Este envolvimiento - apasionado, casi invisible o crítico, negociando realidad con el otro - es justamente lo que diferencia la metodología cualitativa de la cuantitativa y, como pretendo mostrar en este artículo, es tan científico como el otro. ${ }^{2}$

Gubrium y Holstein (1997), en su libro The New Language of Qualitative Method, diferencian cuatro lineas de pensamiento al analizar la metodología cualitativa: Naturalismo, Etnometodología, Emocionalismo y Posmodernismo, las cuales adopto en la estructuración de este texto. Puede parecer que se trate aquí de una presentación evolucionista - esta no es la

\footnotetext{
- Doctora en Antropologia Médica de la Universidad de Hamburgo, Alemania. Profesora del instituto de Psiquiatría - IPUB- UFRJ, coordinadora del centro para personas con enfermedad de Alzheimer y otros transtomos mentales en la vejez - CDA CIPUB/UFFJ.

1 Un ejemplo seria la noticia del Jornal do Brasil titulada "Made in USA": Especialistas en Brasil de la Universidad de John Hopkins, de Baltimore, en el estado de Marytand, hicieron investigaciones en las capitales del Nordeste y descubrieron lo que hasta los coqueiros de Maceió [ciudad brasilera] ya saben. Si la elección fuese hoy. Fernando Henrique Cardoso estaria reelecto. Fue una investigación de tipo cualitativa, aquella que no se preocupa con los indices, sino con lo que va en ef alma dol elector J Jornal do Brasil, i

Intorme $\left.\mathrm{JB}^{*}, 31,07.97: 6\right)$

2 El envolvimiento personal del investigador con las personas y el tema a ser estudiado fue investigado por Devereux (1967), quien, influenciado por el psicoanálisis, mostró el "Miedo y Método
} en las Ciencias del Comportamiento" argumentando que esta interacción emocional siempre está presente en cualquier tipo de investigaciớn. 
intención, por lo menos no en el sentido de "de lo peor a lo mejor". Aungue estos cuatro tipos de pensamiento- y podría haber escogido otros - representen una cierta secuencia históri$\mathrm{ca}$, con diferentes grados de envolvimiento del sujeto, dcl autor, me gustaría proponer que la unión de los cuatro puede significar un análisis más completo, ya que cada uno tiene su valor analítico, pero también sus limitaciones:

\section{El mundo entonces parece como un tejido complicado de acontecimien- tos en los cuales conexiones de dife- rentes maneras alteman o se entre- cruzan o se combinan y así determi- nan la estructura del todo (Heisen- berg, 1958, cit. en Lock, 1984).}

Estos tejidos, percibidos por Heisenberg, difícilmente pueden ser entendidos de una sola manera y tampoco podemos esperar que una inyestigación nos de todas las respuestas. Pero si varias "miradas" se aproximaran a un mismo problema y llegaran a conclusiones compatibles - no necesariamente idénticas como es exigido por las metodologías cuantitativas (cf. Goldenberg, 1977), podríamos trabajar con una realidad válida en aquel momento y que significa el mundo relacional del problema a ser investigado. Es la verdad de Hermes con la sombra del investigador, tanto iluminando como oscureciendo el problema.

\section{Naturalismo}

"Go the people"

El Naturalismo puede ser considerado como una reacción a la "antropología o sociología de gabinete"; a los análisis distantes de la realidad a ser investigada. Las críticas a esta actitud fueron formuladas dentro de la Escuela de Chicago, especialmente por Robert Park, quien en la época recomendaba a sus estudiantes "vayan a ensuciar sus nalgas durante las investigaciones reales" (Gubrium y Goldstein, 1997:6). La regla generalmente adoptada es la del envolvimiento del investigador con la realidad del grupo a ser investigado, sin "going native" (volverse nativo). El grado "cierto" para hablar del mundo "natural" del otro es generalmente adquirido cuando el investigador se siente "aceptado" o cuando consigue revelar "secretos" a los cuales no tendría acceso sin una cierta penetración en la estructura del gxupo. Este proceso de inserción, un tipo de muerte social, es descrito la mayoría de las veces con muchos detalles, dando legitimidad a la verdad y autenticidad a los datos presentados. Estudios clásicos como los de Foote-Whyte (1990 [1943]), Berreman (1990 [1962]) o las "descripciones densas" de Geertz (1989 [1973]) nos revelan la inserción del autor en el campo, el pasaje de la no persona o del "extraño" a alguien aceptado (sin embargo nunca volviéndose un igual), como fue tan bien descrito por Foote-Whyte. ${ }^{3}$ Cuenta Geertz:
A principios de abril de 1958, mi mujer y yo llegamos a una aldea balinesa, atacados de malaria $y$ muy abalados, y en esa aldea pretendiamos estudiar como antropólogos. Un lugar pequeño, con cerca de quinientos habitantes y relativamente alejados, la aldea constituía su propio mundo. Nosotros éramos invasores, profesionales es verdad, pero los balineses nos trataron como parece que sólo los balineses tratan a las personas que no forman parte de su vida y que, mientras, los asedian: como si nosotros no estuviésemos allí. Para ellos, y hasta cierto punto para nosotros mismos, éramos no personas, espectros, criaturas invisibles (Geertz, 1989:278).

Este estado de invisibilidad solamente es interrumpido cuando, por casualidad, la pareja Geertz reacciona según el código local y de repente es percibida por los aldeanos:

\section{Mi mujer y yo estábamos todavía en la práctica del soplo de viento, una práctica muy frustante y ener- vante, en la cual se comienza a dudar si es verdaderamente real, cuando diez días o un poco más después de nuestra llegada fue or- ganizada una pelea de gallos muy disputada...(p. 279).}

Es después de un relato dramático sobre la intervención de la policía en la muy popular pelea de gallos, cuando el matrimonio corrió junto con los jugadores, que la situación cambió:

A la mañana siguiente la aldea era
un mundo completamente diferen-
te para nosostros. No sólo dejamos
de ser invisibles sino que éramos
ahora el centro de todas las aten-
ciones, el objeto de un gran
extravasamento de calor, interésy,
principalmente, diversión (p.282).

No toda iniciación es tan dramática, pero lo que estos relatos tienen generalmente en común es la dramaticidad del encuentro de los dos mundos - el del investigador, muchas veces descrito como ingenuo, hasta rude por no conocer la etiqueta del lugar - y el "mundo nativo" (Geertz se describe, por ejemplo, como invasor o espectro). Pero la persona del autor, una vez

3 El autor después de un tiempo de convivencia con un grupo de jóvenes de un suburbio de Boston, la Street Comer Society, comienza a usar malas palabras y luníardo en las conversaciones, hasta que uno de sus informantes principales, Doc, dócilmente le recuerda que "esto no combina contigo" (Foote-Whyte, 1990). 
accptada, prácticamentc desaparcce del texto y da lugar a la voz del "otro". La perspectiva es ahora de "desintcrés", ya que las presuposiciones del autor deben ser borradas lo máximo posible para que el universo del "otro" se revele a través de sus propias palabras, gestos y rituales. ${ }^{4}$ Crapanzano (op.cit.) observa que en el texto de Geertz el "yo" después de la introducción desaparece y una autoridad invisible toma el lugar a través de la descripción de "ellos". Crapanzano afirma que, a pesar de la narrativa aparcntemente hecha por la mirada de los balineses, en la verdad es el autor, Geertz, quien construye una meta narrativa a través de las elecciones de los detalles contados para el lector y de las atribuciones dadas al observado.

Benninghoff-Lühl (1992) en su artículo "Las palabras me cayeron encima" analiza el choque de las culturas y la muerte social del investigador cuando es confrontado con otras realidades (alemanes en Brasil, por ejemplo). El caos y el miedo raramente son tematizados en los análisis y la inserción en el campo sigue una lógica implícita: la del estado ignorante para la autoridad del saber dcl autor. Solamente en relatos como los diarios de Malinowski (1967), publicados después de su muerte, o el libro de Retum to Laughter de Laura Bohannan, publicado bajo seudónimo (E. Smith Bowen, 1964) cuentan cómo los antropólogos percibían la situación en el campo, con miedo, confusión, disgusto, deseos eróticos reprimidos o hasta odio del grupo estudiado; parte de aquello que Malinowski llamó "explosión de significados", pero nunca revelados en los textos "cientifficos". El envolvimicnto emocional es inevitable y el lazo creado puede scr tematizado. ${ }^{5} \mathrm{Al}$ final ¿quićnes son los informantes: aquéllos que son simpáticos y no nos dan vuelta la cara? ¿A quién le gusta ser entrevistado y a quién no le gusta?; ¿será que este último tiene otro tipo de dato que relata otro aspecto de la realidad? La elección depende en gran parte del autor, de sus preferencias, simpatías y deseos. El abordaje "emocionalista" (ver más abajo) trae, de una cierta forma, un regulador para este tipo de limilaciones, ya que en él, el envolvimieno emocional con el otro crea una nueva realidad, resultado de una "negociación" entre dos mundos encontrándose, y la descripción "naturalista" del mundo del otro ahora se vuclve ilusión.

Tal vez el estudio más radical para meterse en el mundo natural del otro, donde la transición se hace parte del análisis, sea el libro de Favret-Saada (1979) sobre brujería en Bocage, Francia. En él, Ja autora cuenta su envolvimiento con la cultura local, con el acceso a las verdades "filtradas" cuando, inicialmente, interesándose por la brujería - concepto exótico para el intelectual de París - y solamente despuês de enfermar y reaccionar, como en el caso de los Geert\% conforme al código local, ella gana acceso al "mundo de las brujas". Ella no se vuelve bruja sino que el universo donde la brujería es real se vuelve la realidad de ella y el lector se sumerge, junto con la autora, en un mundo paralelo, posible, en relación al conocido por la mayoría. Favret-Saada va más allá de una descripción naturalista, muchas veces considerada como periodística - ella quiere "to- car las fronteras de lo indecible" (p.34). Así, ella sale del Naturalismo y pucde ser considerada emocionalista (cf. abajo).

\section{Etnometodología}

Não falta literatura sobre a grandeza, a paixão, a beleza, o risco do oficio de pesquisador. Ela é abundante demais. Era preciso uma descrip̧āo vista do exterior de um trabalho como qual nos sentimos bastante familiarizados. Deixamos a psicologia para mas tarde (Latour y Woolgar, 1997:34).

Mientras un abordaje naturalista revela la realidad a través de "estar con", la etnometodología, que surgió en los an̄os '60, también en la Escuela de Chicago a través de Garfinkel y colegas, argumenta que la proximidad defendida por el naturalismo es ficticia. Esto es porque la realidad es construída y lo que puede ser descrito es cómo esta realidad es hecha, llamando la atención a Io que muchas veccs consideramos como obvio o "natural". La realidad como construcción es captada a través de la combinación de la fenomenología y el interaccionismo simbólico. En vez de describir la realidad, prácticas constituyendo la realidad son el tema, como por ejemplo, el habla de los actores envueltos a través del análisis del discurso (cf. Sacks, 1972).

La concentración de este método en prácticas de los actores sociales fue muy criticada por ser distante - reduciendo la realidad a un código -, negar la emoción, ser apolítico (p.ej. Frow, 1995:136) y "moralmente vacío" (Holstein y Gubrium, 1997:107). El envolvimiento del autor, aunque presente en el texto, generalmente no atraviesa la línea que divide los dos mundos para no perder la mirada analítica.

Una etnografia que usó la etnometodología como marco teórico principal, mostrando el cnvolvimiento del autor y la construcción de la realidad, sería el libro de Latour y Woolgar (1997 [1979]) sobre la producción de los hechos científicos dentro de un laboratorio de neuroendocrinología en los Estados Unidos. El libro comienza con una introducción de un día típico del laboratorio como si estuviese siendo grabado por una cấmara, solamente registrando:

9.05: Wylie atraviesa la sala y entra
en el escritorio. Dice alguna cosa
apresuradamente, dice que hizo una
gran estupidez. Mandó el artículo...
(el resto no se comprende).
9.05.3: Bárbara entra. Pregunta a
Jean qué tipo de solvente se debe
usar en las colonias. Jean respon-
de de adentro del escritorio. Bár-
bara se va, vuelve para su lugar(...).

9.05: Wylie atraviesa la sala y entra en el escritorio. Dice alguna cosa apresuradamente, dice que hizo una gran estupidez Mandó el artículo... (el resto no se comprende). 9.05.3: Bárbara entra. Pregunta a Jean qué tipo de solvente se debe de de adentro del escritorio. Bár bara se va, vuelve para su lugar(...).

4 Este tipo de pensamiento es diferente de lo que Bourdieu llama de "objetivación". Para Bourdleu la subjetividad del autor noes borrada sino colocada de una forma más critica, como parte del análisis. 
El autor queda espantado delante del ritmo acelerado del laboratorio, las informaciones científicas que solamente entiende en partc y aunque cada vez más forman parte de la rutina del lugar, nunca abandona la posición de extraño.

\section{Al final de algunos meses, este etnólogo francés [B. Latour], bal- buceando apenas el inglés $e$ igno- rante en materia de ciencia, se tor- na invisible (...). Fue entonces que comencé a estudiar seriamente aquel mundo extraño (p.17).}

Al contrario de Gecrtz que sentía su invisibilidad dolorosa, algo a ser vencido para poder comenzar a "trabajar", Latour, de quien son las experiencias de campo (cl segundo autor solamente entra en la hora de analizar el material y escribir el libro), comenzó justamente a enfatizar estc estado como punto de partida de una observación realista. La invisibilidad para el significa no ser alguien extraño en la rutina, influenciando el "mundo natural" del laboratorio. Él observando, pero los otros ignorándolo, es aquí la situación ideal para la investigación de campo.

Nuestra investigación tiene por fi-
nalidad abrir un camino diferen-
te: aproximarse desde la ciencia,
contornar el discurso de los
cientistas, familiarizarse con la
producción de los hechos y después
volverse sobre símisma, explican-
do lo que hacen los investigado-
res, con un metalenguaje que no
deje nada debiendo al lenguaje que
se quiere analizar. En resumen, se
trata de hacer lo que hacen todos
los etnógrafos, y de aplicar la cien-
cia a la deontología habitual de las
ciencias humanas: familiarizarse
con un campo, permaneciendo
independiente de él y a la distan-
cia (p.26, subrayado mío).

El deseo de Geertz de penetrar en las "telas del significado" de la aldea balinesa es descrito casi como peligro metodológico. Solamente un obscrvador distante, con un mínimo de emociones envueltas, consigue descifrar lo que los actores sociales descritos cstán hablando o como actúan "en la verdad". Las palabras de los cicntistas representan un sentido escondido que, así como por ejempio en el psicoanálisis, solamente una mirada diferente, de afuera, puede revelar. Así, Latour, hasta busca el distanciamento de su objeto de estudio:

El etnógrafo de esa investigación fue ayudado por varios factores en su búsqueda de distancia: él era verdaderamente ignorante en ciencia y casi analfabeto en epistemo- logía. Estaba en un mundo realmente exótico, en California, trabajando con una lengua extranjera, el inglés. Casi no tenia juicios previos sobre la verdad cientifica, en relación a la cual era, digamos, agnóstico. Finalmente, estaba llegando del África y podía aplicar, en el caso de los cientistas, un aparato para poner a los salvajes a distancia, aparato fuera de moda en antropología, pero perfectamente adaptado en el Institute Salk, una vez que de manera polémica permitía que a cada nueva tentación de tornarse cientista recordara el mandamiento: "Haz lo que quieras pero el lenguaje de ellos no puede tornarse tu metalenguaje" (p.27).

Latour admite que "poner los salvajes a distancia" está fuera de moda en la antropología. Sin embrargo, tratándose de un mundo que funciona dentro del mismo universo referencial del pesquisador, él precisa adoptar esta medida para no perder su "ingenuidad" y "distancia": "Ellos cuentan, nosotros contamos, ellos experimentan, nosotros experimentamos, ellos construyen, nosotros construímos. Las diferencias vendran después" (p. 30). El investigador se vuelve un "caballo" como se dice en el umbanda. El quicre dejar hablar y revelarse a los propios protagonistas, de preferencia sin la intervención del investigador:

En lugar de imputar a los actores
sociales, cada vez, intereses, cál-
culos, clases, hábitos, estructuras,
suponiéndolos marionetas de la
sociedad, la etnometodología quie-
re vaciar la sociología de todo su
meta lenguaje y quiere tomar al
actor y su práctica como el único
sociólogo competente. Entre el so-
ciólogo charlatan y el actor, es
mejor confiar en el actor (p.28).

Latour y Woolgar, para dar todavía más credibilidad a su distanciamento analítico, inventan, para cada capítulo, un observador diferente que lanza luz sobre el laboratorio investigado de diferentes ángulos. No son ellos (por qué no?) los que hablan sino la subjetividad aquí revelada (e inevitable, creo), la que no es real sino "solamente inventada".

Esta mirada distante revcla, en el libro de Latour y Woolgar, cómo los enunciados científicos se tornan hechos y realidad dentro de un contexto socio-cultural especial como la comunidad científica moderna occidental y no son algo natural, un día descubierto, como la historia de las ciencias nos hace creer muchas veces. Sin embargo, este mirar "frio" solamente puede 
revelar una parte de la realidad; otra parte, el "mundo emocional", será discutido en seguida.

\section{Emocionalismo}

We live for feelings

(Jack Douglas, 1977)

La realidad no puede ser reducida a un código ni se ofrece como una tierra incógnita, esperando que el investigador atraviese la frontera para cazar las mariposas coloridas. Por eso, algunos autores, con raíces en el existencialismo, argumentan que la profundidad de una experiencia difícilmente puede ser captada con nuestro lenguaje común y racional.

Descie los años ' 80 el foco en experiencias interiores y emoción surgieron como crítica a la sociología y antropología tradicionales. El lugar del análisis es principalmente el cuerpo del propio investigador, donde las emociones, que surgieron en el contacto con el otro y su realidad, son las fuentes del análisis.

Las emociones como discurso fucron presentadas como no universaies y producidas culturalmente (Lutz, 1998; Hochschild, 1990). Por otro lado, son sentidas como tan profundas, que un modclo analítico como el ofrecido por el Naturalismo o por la Etnometodología no bastarían para transmitir aquelia sensación única, casi indivisible (Holstein y Gubrium, 1997), el "brute being" (Jack Douglas). El emocionalismo podría ser descrito como un Naturalismo radical, ya que muchos actores intentan. sumergirse tan profundamente en la experiencia del yo-eninteracción-con-el-otro que la frontera entre el mundo del autor y del grupo investigado desaparece y una nueva realidad surge, una negociada entre los dos mundos -un punto que también podemos atribuir al Posmodernismo. De esta manera, la constitución de la realidad y la línea que existe o no entre los dos mundos, a veces no puede ser problematizada. (Dentro del Naturalismo exíste, pero el autor está convencido que puede ser superada; la Etnometodología tiene justamente esta línea de separación como tema.)

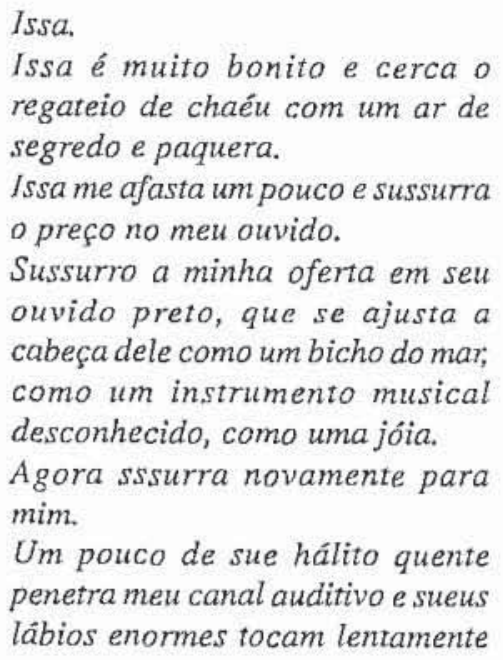

Um pouco de sue hálito quente penetra meu canal auditivo e sueus lábios enormes tocam lentamente

a pele do exterior do meu ouvido. Assim que näo somente escuto as palavras, o francês suavemente colorido pelo acento, mas tambén sinto como ele é formado (Hubert Fichte, Afrika, 1990:335).

Fichte, antropólogo alemán, creaba imágenes con palabras a través de las cuales intentaba evocar en el lector lo que fue sentido en el pasado (mnemosync). La palabra se identifica con el mundo, "la convicción mágica del habla", la "palabrarización del mundo" (cf. Böhme, 1992): es la relativización de lo propio en el espejo del otro lo que Fichte quería cxpresar. Para ćl, la propia palabra carga "Ia magia" de lo representado, está prácticamente viva. Así, como otros pocos autores, Fichte combate los abordajes positivistas en la aproximación al otro:

La deshumanidad, el desprecio por
el habla en las ciencias humanas
llegan a tal punto que existen in-
vestigadores que, sin hablar una
palabra de portugués, trabajan
sobre el sincretismo brasileiro,
publican sobre enfermos mentales
africanos, sin hablar ninguna len-
gua africana... Ahí, el caläo cien-
tífico se torma una expresión de un
mero neocolonialismo (cit. en
Böhme, 1992:31).

Lo que Fichte llama "antropología poética", en primer lugar es una crítica ácida a la mayor parte de la ciencia contemporánea. Para nosostros es de gran interés porque él, de una forma única y radical, incluye la subjetividad del autor en interacción con la realidad del otro: inseparables, cargados de emociones de aquel momento en creación.

Un relato menos radical, pero también sobre la incorporaciôn del encuentro con el otro, es el tema de Robert Desjarlais (1991, 1992) que estudió los rituales de cura entre los Yolmo, en el Himalaya. Él considera la discusión reciente en las ciencias sociales en torno a las emociones (como discurso) exigiendo no reconsiderar emociones - por ejemplo: considerar una canción en la cual se expresa que se extraña como una protesta política - pero sin tomar en cuenta el significado de, digamos, canciones de luto o poesías de amor, porque si no "olvidamos estas cosas llamadas amor; extrañar, y desesperación" (1991:338). Despućs de estas afirmaciones, el autor, en su artículo de 1991 continúa con un metatexto, explicando al lector "cómo ellos sienten emociones". Aquí Hermes-autor quedó casi invisible detrás de las frases y constataciones. La autenticidad del análisis de su libro, aunque publicado un año más tarde, es revelada a través del propio envolvimiento en las prácticas de cura. Dentro de la "antropología de los sentidos" [anthropology' of the senses], que tiene un background fenomenológico, Desjarlais describe cómo experimenta el trance, en el que el chamán e informante principal del autor (Meme) practica su medicina: 
Durante muchas ceremonias entré en un 'estado de trance' que me convenció completamente. Sin embargo, sin duda, era distinto de lo que los chamanes de los Yolmo experimentaban cuando los dioses "cayeron" en su cuerpo (...). Mi propio trance sucedía paralelamente a la bajada de los dioses de Meme en su cuerpo (...). En el momento en que Meme comenzaba a sentir la presencia de lo divino, su cuerpo oscilaba en ataques $y$ temblores, y mi cuerpo seguía el ritmo de sus acciones temblando semejantemente. Rodeado por el repercutir insistente del tambor del chamán, mi cuerpo se iba a llenar con energía. La música resonaba dentro de mí, aumentando, llenando mi cuerpo y el cuarto con significado de impacto. Ondas de temblores corrian por mis extremidades. Centellas volaban, colores que se expandían, el cuarto quedó con vida por las voces, el fuego, las risas, la oscuridad (p. 5).

En forma diferente a la de Fichte, que aparentemente no se preocupa de la autenticidad de los datos ofrecidos al lector, Desjarlais se cuestiona sobre hasta qué punto un autor puede sentir el mundo sensorial-emocional del otro, y más todavía, escribe procurando que la experiencia tenga sentido para el lector. $\mathrm{Al}$ leer otros autores que pasaron por una experiencia de aprendizaje donde el trance formaba parte, él cuestiona esos relatos que parecen siempre un relato en el cual las imágenes evocadas por los etnógrafos fuesen, después de un cierto tiempo de iniciación, las mismas del curandero o chamán:

Los estados de trance que yo conocia, diferente de los relatos que había leido, sugieren que el proceso de conversión cultural o traducción no es tan nítido. Los mundos escondidos no eran los mismos. Aunque yo me "sacudiera" al mismo tiempo que Meme, sugiriendo una base fisiológica del trance, estaba lejos de ser idéntico a lo que mis vecinos estaban acostumbrados (...) Los niños se reían de las contorsiones que hacía mi cuerpo y los adultos reían para adentro sobre mis relatos de aquello que veía cuando me estaba "sacudiendo" (aunque el mero hecho de mi trance parecía reafimar para los aldeanos la realidad de sus dioses y' mi habiliddad para recibirlos) (p.15).

Para Desjarlais, aprender el trance no significaba solamente estudiar con Meme, sino incorporar sensualmente el mundo que lo rodeaba, frecuentar las casas de té, sentir los olores y ruidos de este mundo diferente - lo que Bateson llama el deuterolearning. ${ }^{6}$ Desjarlais considera entonces la historia de sus trances como una transcripción sensorial de una conversión entrc dos culturas y sus maneras de ser. Después de un tiempo, e! autor, aunque nunca libre de las presuposiciones de su propia cultura, sentía como lentamente quedaba "socializado" -lo que el chamán Meme también parecía percibir-, colocando cada vez más el tambor en las manos del americano. Mientras Fichte aparenlemente no cuestiona este nuevo ser, el yo transformado en el contacto con el otro, Desjarlais siente la transformación como alguien en la "tierra de nadie", entre dos culturas. Esta "arqucología del sentido" revela para el autor justamente lo que existe abajo de la superficic, diferente de la "arqueología del saber" de Foucault que da prefercncia a la lingüística, to discursivo y lo cognitivo. La dificultad está en captar aquéllo, que en gran parte va siendo incorporado sin darse cuenta. Después de un tiempo en la villa, el autor cuenta que su cuerpo parecía diferente, moviéndose en el espacio cultural de los Yolmo.

De todos modos, Desjarlais, de acuerdo con Geertz (1984), alerta para que este proceso no se confunda con empatía, ya que este concepto parte de una noción en que lo que el otro está sintiendo puede ser también sentido por alguien. Solamente una percepción profunda, "visceral", puede crear algo parecido con la empatía, pero nunca ser igual a la experiencia del otro, especialmente cuando el mundo referencial está basado en conceptos tan distintos como el nepaiés y el norteamericano.

La "experiencia visceral" del otro en interacción con el propio mundo, busca muchas veces medios de representación en las ciencias, poesía, películas o teatro, por cjemplo: Probablemente de ninguna manera es transmitido mejor el olor, la sensualidad, el escalofrío y lo extraño como aquí. Por otro lado, la pasión, como el amor, es ciega,y así la profundización en las propias pasiones puede restringir la mirada analítica a una 'autopsia' del sujeto o limitarse a un relato narcisísta. De todas formas, una ciencia "emocional" revelaría datos que enriquecerían los análisis convencionales y acabarían con la falsa neutralicad de los "datos hard". El Posmodernismo, analizado a continuación, tiene mucho en común con el Emocionalismo. 


\section{Posmodernismo}

COMO ERA BOM

- tempo em que Marx explicava

o mundo

tudo era luta de classes

como era simples

o tempo em que Freud explicava que édipo tudo explicava tudo era clarinho limpinho

explicadinho

tudo mais asséptico do que era quando eu nasci hoje rodando sambado pirado descobri que é preciso aprender a nascer todo dia.

(Chacal)

El discurso posmoderno enfatiza cada vez más la reflexividad cntre método y realidad social - que el método construye realidad. Aunque cl posmodernismo tenga muchas voces, algunos aspectos como la desconstrucción y la incerteza de la realidad o una única metanarrativa pueden ser mencionados. Se ofrecen "lecturas" y no "observaciones", "interpretaciones" y no "descubrimientos" (Gubrium y Holstein, 1997). La [hiper-] realidad transmitida a través de los medios electrónicos es creada por una "socieđad dramatúrgica" (Denzin, cit. en Gubrium y Holstein, 1997:81). ${ }^{7}$ Diferente de Goffman, para quien la vida contemporánea era parecida a un teatro y descrita en un orden intcrnacional, la sociedad posmoderna es teatral. Contrastando este abordajc con el emocionalismo, podemos citar a Denzin:

Por debajo del sistema de amor romántico y su renovación de los significados tradicionales de familia y casamiento, espera lo hiperreal, la mentira, la simulación, el orgasmo simulado, y las verdades sexuales sobre la sexualidad masculina y femenina... es un casamiento de conveniencia. No refleja lo que es real, lo que verdaderamente es sentido sino lo que es pretendido, lo que parece ser apropiado, no lo que es. Lo hipereal de Baudrillard se tomó real, la mentira se tomó verdad... (en Gubrium y Hoistein, 1997: 83).

La negación de autoridad de las "grandes teorías" y la "crisis de las representaciones" también cuestiona cada vez más la autoridad del autor como representante de lo verdadero. Mientras Desjariais aún coloca los propios sentimientos como reales (aun- que sólo parcialmente representando la reaiidad del otro), los sentimientos como los describe Denzin son sentimientos fake falsos) dentro de una realidad fragmentada, pasajera, indeterminada, $y$ donde las personas ofrecen $y$ viven diferentes papeles. El autor se posiciona desde un punto de vista reflexivo delante de este mundo, de una forma pragmática, intentando captar voces y narrativas hasta contradictorias de una misma realidad, deshaciendo la autoridad del autor, colocando su punto de vista como "solamente una narrativa más", un "juego de lenguaje" entre otros.

El libro Forbidden Narratives [Narrativas Prohibidas] de Kathryn Church podría servir como ejemplo. Lo "prohibido" se refiere justamente a la inclusión de la subjetividad de la autora en el mundo de los "sobrevivientes psiquiátricos", que es como llama a las personas que salieron de psiquiatría y ahora sc están organizando en un programa de salud mental en la comunidad, en Toronto, Canadá, Pero el mundo de los "sobrevivientes psiquiátricos" es descrito a través de los ojos de la autora. El primer capítulo se llama "Comenzando desde el "yo"" (Beginning from ' $I$ ') donde relata el propio envolvimiento con la salud mental en relación a su autobiografía. "Mi investigación de doctorado empezó con las cuestiones persistentes, perturbadoras, frustrantes y ardientes sobre mi propia práctica como organizadora en la salud mental y después como investigadora" (1995:2). Church advierte su orientación teórica como influenciada por cl pos estructuralismo feminista - que describe como una orientación "de maneras menos fijas y determinadas"- y hace notar, al mismo tiempo, un envolvimiento cada vez mayor como el que Jackson llama de "antobiografía crítica", el "permiso para hacer algo que académicos raramente hacen: inscribirme en mi propio trabajo como un carácter mayor"(1995:3). La relevancia de estc procedimiento para la temática elegida es explicada por ella del siguiente modo:

Yo realmente pretendía ser "objetiva" en relación a mi trabajo con los sobrevivientes psiquiátricos, pero las realidades del enganche genuino imposibilitaron literalmente el intento de no entrar en la subjetividad. Estaba confrontada con las complejidades de situarme como una "outsider" en relación al movimiento hecho por personas que tienen una historia de opresión por un sistema de servicios en el que yo trabajaba. En su intento de entender aquello, los sobrevivientes me pidieron una manera particular de participación: querian que fuese personal (...) enfrentando este desafio entré en un proceso de desconstrucción profesional y personal (ibid. p. 3).

7 El periodista y politico argentino Aníbal Ford llama la atención sobre el abismo que existe entre la mayoría de las sociedades latinoamericanas entre la esfera material (calle) y la simbóloca (televisión), diferente del "primer" mundo. Para él, este hecho puede ser una chance para no quedar totalmente "massmediatizado"y prevenir que el espacio público sea reducido a la televisión; como sucede en Europa (Taylor, 1997). 
Church ofrece, a continuación, discursos diferentes que, en este campo de pesquisa, la de una etnografía de los "sobrevivientes psiquiátricos", ofrecen maneras competitivas de dar significado al mundo en acción. Pero ella nunca niega que lo que percibe como relevante y lo que es transmitido para el lector no pasa por ningún filtro de la propia autobiografía y las emociones envueltas. La propia enfermedad de la autora, los dolores que ella siente, la autodefinición delante de los "sobrevivientes", etc., son puntos influyentes para ella, pero al mismo tiempo, enriquecen los datos, ya que...

...existe aqui un desafio a las convenciones (dominantes masculinas) sobre lo que puede ser discutido en ambientes académicos o en consultas públicas (...) Existen algunos que declaran las emociones como académicamente legitimadas... pero realmente las emociones estan incluidas... Es el deseo por estas cualidades desterradas que está atras de la decisión de incluir mi propio cuerpo (enfermo) en este texto. Tomando esta decisión, lo "público", lo "teórico" y lo "racional" no fue sacado. En verdad, esto sugiere que lo que experimentamos y presentamos de nosostros como subjetivo y personal, es simultaneamente objetivo y público (ibid. p.3).

Distinto de lo que planteaba Desjarlais que analizaba las emociones incorporadas, sintiéndose íntegro, aunque en un proceso de constante cambio (influenciado por el encuentro con la realidad ajena), Church define su subjetividad, citando a D. Jackson, como sustituyendo...

\section{...el self esencial y auténtico. En vez. de un self singular y estático espe- rando a ser desenterrado, el posestructuralismo descentraliza el self tradicional e introduce la posibilidad de selves múltiples, mucho más fragmentados y contra- dictorios... formados socialmente en condiciones, relaciones y refe- rencias cambiantes (p. 7).}

Sus visiones como antropóloga no coinciden con las de la antigua trabajadora en salud mental, ni con la mirada de una persona enferma, compañera de un hombre con intereses propios, persona politizada, feminista o como intelectual. Mientras Desjarlais dejaba al lector experimentar la cultura por él investigada a partir de las sensaciones que experimentaba en su cuerpo, el libro de Church prácticamente no habla nada de la cultura de los "sobrevivientes". Su subjetividad individualizada toma un espacio tan grande que la contextualización del propio cuerpo solamente sucede de pasaje. La realidad de su "objeto" de estudio, la salud mental de un determinado grupo, prácticamente no entran en el foco y el interés de la autora:

Tengo el hábito de nunca mirar
películas sobre salud mental. No
es porque no crea en la salud men-
tal, sólo que dejé de lado el debate
sobre lo que es. Aún existen gru-
pos de personas que se encuentran
para hablar sobre lo que es una
enfermedad mental, pero eso es un
debate intelectual del cual no quie-
ro participar más. (..) No estoy tan
interesada en salud mental sino en
lo que sucede cuando decidimos
hablar de la manera como lo ha-
cemos (p. 40 ).

La subjetividad de Church se revela a través de varias voces, cada una hablando de una faceta de su personalidad y formación intelectual, recordando el "romance polífono" de Bachtin, pero aquí los discursos diferentes se encuentran unidos en una única persona que se presenta como fragmentada.

\section{Conclusión}

Mucho más podría ser dicho en relación a los cuatro abordajes aquí presentados. La reflexión de cada uno sobre el papel del autor revela datos y hasta realidades diferentes; tienen sus limitaciones y ofrecen desafíos. No se trató de elaborar aquí un texto didáctico sino de ofrecer una reflexión de aquello que Zeus entendió, pero muchos investigadores no: que la verdad que revelamos como un texto siempre depende de la metodología que aplicamos, nuestros segundos ojos. Y que una metodología sería ciega en el caso que no tuviese ojos con los que mirar, el "sujeto posicionado" de Bourdieu (1977). La subjetividad reflexiva como dato analítico simplemente aumenta el valor heurístico de una investigación y da "alma" al texto, no en el sentido religioso (por lo menos no en primer lugar), sino en el sentido de lo que decía Hacking cuando planteó considerar el alma como aquello que debería estar siempre en el "fondo" del metalenguaje científico, aquello que "invoca el carácter, elección reflexiva, autoconocimiento, valores que incluyen honestidad con los otros y hacia sí mismo, y varios tipos de libertad y responsabilidad"(1995:6).

\section{Agradecimientos}

Agradezco a la Dra. Teresa Durán Pérez por el interés en mi trabajo y a Eduardo Mutazzi por la traducción đel portugués al español. 


\section{Bibliografía}

BECKER, H. S. (1997 [1992]), Métodos de pesquisa em ciências sociais, Hucitec, Säo Paulo.

BENNINGHOFF-LÜHL, S. (1992), "'Wörter stürzten auf mich ein', Kulturschock, Gestāndnis und die Konstruktion von Wissen in ethnographischen Texten", en Kea, Zeitschr. f. Kulturwissenschaften 3: 56-72.

BERAEMAN, G. (1990), "Por detrás das muitas máscaras," en Desvendando máscaras sociais, A. Zaluar Guimarães (org.), Francisco Alves, Fio de Janeiro, pp. 123-176.

BÖHME, H. (1992), Hubert Fichte, Riten des Autors und Leben der Literatur, J.B. Metzlersche Verlagsbuchhandlung, Stuttgart.

BOUAD!EU, P. (1977), Outline of a theory of practice, Cambridge University Press, Cambridge.

CAVALCANTI, M.T. (1996), "Ética e assistência à saúde mental", en Ética e saúde mental, A.C. Figueiredo e J. Ferreira da Silva Filho (orgs.), Topbooks, Rio de Janeiro, pp. 73-84.

$\mathrm{CHURCH}, \mathrm{K}$. (1995), Forbidden narratives. Critical autobiography as social science, Gordon and Breach, London.

CLIFFORD, J. (1993), "Über ethnographiscine Autorität", en Kultur, Soziale Praxis, Text, Die Krise der ethnographischen Repräsentation, E. Berg e M. Fuchs (orgs.), Suhrkamp, Frankfurt/M, pp. 109-157. CRAPANZANO, V. (1986), "Hermes' Dilemma: The masking of subversion in ethnographic description," en Writing culture. The poetics and politics of ethnography, J. Clifford e G.E. Marcus (eds.), University of Callfornia Press, Berkeley, pp. 51-76.

DESJARLAIS, R.R. (1991), "Poetic transformations of Yolmo 'sadness"', en Culture, medicine and psychiatry 15: 387-420.

DESJARILAIS, R.R. (1992), Body and emotion. The aesthetics of illness and healing in the Nepal Himalayas, University of Pennsylvania Press, Philadelphia.

DEVEREUX, G. (1976 [1967]), Angst und Methode in den Verhaltenswissenschaften, Ulistein, Frankfurt/M

FAVRET-SAADA, ง. (1979), Die Wörter, der Zauber, der Tod, Der Hexenglauben im Hainland von Westfrankreich, Suhrkamp, Frankfurt/M. FlCHTE, H. (1990), "Afrika", en Psyche, die Geschichte der Empiindlichkeit, Fischer Frankfurt/M, pp. 279-510.

FOOTE-WHYTE, W. (1990), "Treinando a observação participante", en Desvendando máscaras sociais, Alba Zaluar Guimarāes (org.), Francisco Alves, Rio de Janeiro, pp. 77-86.

FROW, J. (1995), Cultural studies and cultural values, Oxford University Press, Oxford.
GEERTZ, C. (1989), "Um jogo absorvente: Notas sobre a briga de galos balinesa," en A interpretação das culturas, Guanabara Kogan, Ric de Janeiro, pp. 278-321.

GEERTZ, C. (1984), "From the native's point of view': on the nature of anthropological understanding", en Culture theory. Essays on Mind, Self, and Emotion, R.A. Shweder \& R.A. L.e Vine (orgs.), Cambridge University Press, Cambridge, pp. 123-136.

GOLDENBERG, M. (1997), A arte de pesquisar. Como fazer pesquisa qualitativa em ciências sociais, Record, Rio de Janeiro.

GUBRIUM, J.F.y J.A. HOLSTEIN (1997), The new language of qualitative method, Oxford University Press, New York.

HACKING, I. (1995), Rewriting the soul, multiple personality and the sciences of memory, Princeton University Press, Princeton.

HOCHSCHILDT, AR. (1990), Das gekaufte Herz, zur Kommerzialisienng der Gefühle [The managed heart, commercialization of human feelings] Campus, Frankfurt/M.

LATOUR, B. y S. WOOLGAR (1997 [1979]), A vida de laboratório. A produçāo dos fatos científicos, Relume Dumará, Rio de Janeiro.

LEIRIS, M. (1978 [1930]), Das Auge des Ethnographen, H. J. Heinrichs (org.), Syndikat, Frankfurt/M.

LOCK, M. (1984 [1980]), East Asian medicine in urban Japan. Varieties of medical experience, University of California Press, Berkeley.

LUTZ, C. (1988), Unnatural emotions: Everyday sentiments on a Micronesian atoll and their challenge to westem theory, University of Chicago Press, Chicago.

MALINOWSKI, B. (1989 [1967]), A diary in the strict sense of the term, Stanford University Press, Stanford.

RORTY, R. (1994), "Method, social science, and social hope," en The postmodern turn. New perspectives on social theory, S. Seidman (org.) Cambridge University Press, Cambridge.

SACKS, H. (1972), "An initia! investigation of the usability of conversational data for doing sociology," en Studies in social interaction, G. Sudnow (org.), Free Press, New York, pp. 31-74.

SMITH-BOWEN, E. (1984 [1964]), Rückkehr zum Lachen [Return to laughter], D. Reimer, Berinn.

TAYLOR, J. (1997), "Pueblo chico, infierno grande - Small town, iarge hell: Toward the global village?", en Cultural producers in perilous states, G.E. Marcus (org.), The University of Chicago Press, Chicago, pp. $357-370$. 